\title{
From the runway to the airway and beyond
}

\section{K Henriksen, F Moss}

\section{Embracing simulation and team training-now is the time}

$\mathrm{E}$ d Link had an early fascination with flying, yet the expensive costs of plane rentals and fuel to practice his piloting skills were beyond his modest salary as a tuner of pianos and organs. So in 1928, using organ parts, bellows, and compressed air, he finished construction of a mechanical device he called the "pilot maker" (see http:// www.link.com/history.html). It had short wooden wings with a fuselage mounted on a universal joint, capable of pitching and rolling while the fledgling pilot worked the controls. Further improvements to the device in the 1930s enabled pilots to train to fly in adverse weather guided by instruments, ushering in the era of modern day training simulators. During wrld wr II, tens of thousands of pilots were trained in Link simulators, and a period of phenomenal growth and technological sophistication followed. ${ }^{1}$ Link's creation changed the course of aviation history, spawned a multi-billion dollar flight simulation industry, and continues to exert influence in distal disciplines such as health care, to which this supplement gives testimony.

Today's commercial aviators know that "stick and rudder skills" are not enough to ensure safe and reliable flights. Convergence of accident data with NASA research data demonstrated that safety was compromised by preoccupation with minor mechanical problems and inadequate leadership. ${ }^{2}{ }^{3}$ Crew resource management (CRM) emerged in the 1970s when it was recognised many pilots lacked "the right stuff" to manage aircrews effectively. Training was needed to overcome failures to delegate, to assign responsibilities, to set priorities, to use available data, to communicate intent and plans, and to monitor progress. ${ }^{45}$

Health care providers work together, but are trained in separate disciplines.
Few receive training in teamwork. ${ }^{67}$ Recent emphasis on safety has highlighted this training gap, particularly in settings characterised by rapid paced operations, risk, and uncertainty. The breakdowns that occur in operating rooms, including failing to brief plans for operation, to speak up, to inform teams of workload or about patient problems, to articulate courses of action, to establish leadership and to recognise conflicts, are very similar to aircrew performance deficiencies. ${ }^{5}$ But to benefit from others' experiences, the unique conditions of each clinical care setting must be taken into account and technologies and methodologies adapted appropriately.

This supplement, funded by the Agency for Healthcare Research and Quality (AHRQ) and the Department of Defense, explores the development of simulation and team training within health care. Gaba leads off with a conceptual schema for capturing diverse aspects of medical simulation while Cooper and Taqueti provide a brief history of mannequin simulation. Surgical simulation and surgical team training gets its due in articles by Fried, Aggarwal, and Healey and their colleagues. The use of simulation is further described for medical licensing (Dillon et al), for objective structured clinical examinations (Battles et al), and for training teamwork skills (Beaubien et al). The measurement of teamwork during neonatal resuscitation is the focus of a paper by Thomas et al, while Wright et al underscore the importance of situation awareness in simulated medical environments. Hamman discusses the complexity of team training and shares valuable perspectives from aviation; Flin and Maran draw from aviation psychology research, describing a non-technical skills behavioural rating system for anaesthetists; and Leonard and associates describe a broad based initiative in applying human factors principles to ensure effective teamwork and communication across multiple clinical domains. Finally, the development of team training skills in medical education in Denmark is described by Østergaard et al while Burke et al share some lessons learned and practical guidelines on teamwork from military and aviation applications.

An underlying theme tying many of the papers together is that significant gains in patient safety and quality of care will not be made by applying the same orthodoxy and routines that helped give rise to the safety and quality deficiencies of the recent past. New approaches are needed. The authors explore new methods and concepts that will enable health care to more proactively shape the changes that are needed.

Qual Saf Health Care 2004;13(Suppl 1):i1

\section{Authors' affiliations}

K Henriksen, Human Factors Advisor for Patient Safety, Agency for Healthcare Research and Quality, Center for Quality Improvement and Patient Safety, Rockville, USA

F Moss, Editor, QSHC, BMJ Group, BMA

House, Tavistock Square, London, UK

Correspondence to: Dr K Henriksen, Human Factors Advisor for Patient Safety, Agency for Healthcare Research and Quality, Center for Quality Improvement and Patient Safety, 540 Gaither Road, Rockville, MD 20850, UŚA; KHenriks@ahrq.gov

\section{REFERENCES}

1 Flexman RE, Stark EA. Training simulators. In Salvendy G, ed. Handbook of human factors. New York: John Wiley \& Sons, 1987.

2 In: Cooper GE, White MD, Lauber JK, eds. Resource management on the flightdeck: proceedings of a NASA/Industry workshop. NASA CP-2120. Moffett Field, CA: NASA-Ames Research Center, 1980

3 Ruffell Smith HP. A simulator study of the interaction of pilot workload with errors, vigilance, and decisions. NASA Technical Memorandum 78482. Moffett Field, CA: NASA Ames Research Center, 1979.

4 Lauber JK. Foreward. In: Wiener EL, Kanki BG Helmreich RL, eds. Cockpit resource management. San Diego: Academic Press, Inc, 1993.

5 Helmreich RL, Merritt AC. Culture at work in aviation and medicine: national organizational and professional influences. Aldershot: Ashgate, 1998.

6 Institute of Medicine. Crossing the quality chasm - a new health system for the 21 st century. Washington, DC: National Academy Press, 2001

7 Greiner AC, Knebel E, eds. Health professions education: a bridge to quality. Washington, DC: National Academy Press, 2003. 